\title{
EDUCAÇÃO E VOLEIBOL NO ENSINO FUNDAMENTAL SÉRIES FINAIS DAS ESCOLAS DE FOZ DO IGUAÇU
}

\section{ARTIGO ORIGINAL}

SANTOS FILHO, Manoel Germano dos ${ }^{1}$

DEBALD, Blasius Silvano ${ }^{2}$

SANTOS FILHO, Manoel Germano dos. DEBALD, Blasius Silvano. Educação e voleibol no Ensino Fundamental séries finais das escolas de Foz Do Iguaçu. Revista Científica Multidisciplinar Núcleo do Conhecimento. Ano 06, Ed. 01, Vol. 04, pp. 75-91. Janeiro de 2021. ISSN: 2448-0959, Link de acesso: https://www.nucleodoconhecimento.com.br/educacao-fisica/educacao-e$\underline{\text { voleibol }}$

\section{RESUMO}

O presente artigo buscou por meio da revisão bibliográfica e da aplicação de questionário semiestruturado coletar dados e infográficos sobre o voleibol enquanto disciplina escolar, bem como em que medida sua prática influencia o processo de aprendizagem deste esporte em estudantes do Ensino Fundamental. A questão estruturadora da pesquisa foi: quais são os argumentos que definem os padrões de comportamento responsáveis pelo estímulo e desestímulo à prática esportiva do voleibol no contexto escolar? Por esta questão, foi aplicado um questionário semiestruturado cujo foco era revelar a percepção dos entrevistados sobre a abordagem de ensino do voleibol na prática de Educação Física Escolar no Ensino Fundamental. Os resultados revelaram que os agentes desestimuladores à prática deste esporte na escola são: a falta de oportunidades, locais inadequados para sua prática e poucos recursos disponíveis. Como agentes estimuladores, as entrevistas

\footnotetext{
1 Especialista em Educação Física Escolar.

2 Doutor em Educação.
} 
revelam que a influência familiar, da mídia, oportunidades, locais apropriados e investimentos promovidos pelas instituições educacionais, além de uma didática que valoriza o lúdico, o prazer e o convívio social são fatores que contribuem para que este esporte seja indispensável no processo de aprendizagem dos estudantes.

Palavras-chave: Voleibol, Ensino Fundamental, Educação Física.

\section{INTRODUÇÃO}

O Brasil é hoje referência mundial no que diz respeito ao voleibol, conquistou ao longo de três décadas títulos mundiais e olímpicos. Entretanto, é interessante refletir que estes resultados não surgiram ao acaso. São frutos de um trabalho contínuo de investimentos e estímulos à prática massificada do esporte pela população em geral. Os chamados trabalhos de categoria de base, geralmente extra escolares, supriram as demandas futuras de novas gerações de campeões. Tudo isso fez do Brasil uma potência neste esporte.

Segundo colocado na preferência nacional dos jovens nascidos na década de 1980 que testemunhou conquistas importantes nessa época como medalhas em olimpíadas e mundiais da modalidade. Por proporcionar a participação de pessoas de diferentes idades na mesma equipe, de pouco condicionamento físico e também por não ter contato direto com o adversário, faz do voleibol um meio de fácil socialização. Tem como características que são benéficas para o desenvolvimento motor: a precisão e velocidade (CONFEDERAÇÃO BRASILEIRA DE VOLEIBOL, 1995).

Contudo, vale salientar que este processo glorioso do esporte não surge somente nos clubes de alta performance, ao contrário, este processo tem início na escola, onde os alunos têm pela primeira vez o contato com as diferentes modalidades desportivas, e recebem informações básicas sobre cada uma delas e que são replicadas pela mídia nas transmissões esportivas reforçando, desta forma, o que se aprende na escola.

Nesse aspecto, compete aos profissionais da Educação Física utilizar metodologias, materiais, espaços e conhecimentos que consigam atingir as expectativas dos alunos, 
de forma a promover a prática do esporte como a atividade física, valendo-se dos benefícios advindos dele. Esta pesquisa buscou revisar estudos já desenvolvidos sobre o voleibol disponíveis em livros, artigos e infográficos sobre os benefícios de sua prática para a formação educacional de jovens. Por esta razão, realizou-se pesquisa de campo, com emprego de questionário semiestruturado em escolas de Ensino Fundamental, públicas e particulares, do município de Foz do Iguaçu.

\section{VOLEIBOL NA EDUCAÇÃO FÍSICA}

Para Araújo (1994), o Brasil é carente de Educação Física escolar. Para este autor, as qualidades físicas observadas em estudantes de escolas públicas poderiam ser desenvolvidas com maior frequência se houvesse um estímulo maior à prática esportiva nas escolas de educação básica, como, aliás, o são, em outros países. Nesses países, o jogador quando chega a uma equipe de competição já é um atleta formado, apto a receber o treinamento técnico individual, sem limitações funcionais.

Já para Mesquita (2002), o processo de formação inicial assume um papel determinante. Tal afirmação encontra suporte no fato da obtenção de elevados níveis de prestação no auge da carreira desportiva passar, inquestionavelmente, pela realização de um trabalho a longo prazo. Este, para recolher os frutos desejados, no momento certo, necessita se assentar em bases sólidas devidamente estruturadas.

Para tal conta a definição clara e precisa de objetivos em cada uma das etapas de formação, desde a iniciação passando pelo aperfeiçoamento até chegar à especialização. Nesse sentido, percebe-se que o professor tem grande responsabilidade, no que diz respeito à elaboração de aulas que tenham um foco na requisição das habilidades e capacidades físicas adquiridas pelos alunos.

Scarpato (2007), afirma que o professor deve oferecer atividades físicas em que os alunos tenham de realizar ações motoras mais complexas dentro de um contexto em que tenham de escolher entre duas ou mais ações. 
Ou seja, o professor, no desenvolvimento das aulas de Educação Física deve objetivar além das ações motoras, o entendimento dos sistemas de jogo, os conteúdos históricos, as mudanças evolutivas nas regras, como também, utilizar a prática esportiva como instrumento para estimular a reflexão sobre suas ações e atitudes diante dos outros alunos e todas as suas relações sociais. Neste aspecto, a Educação Física Escolar deve estar preocupada em oferecer as mesmas oportunidades a todos, indiferente de sexo, estatura, habilidade ou condicionamento físico.

O olhar do profissional ao traçar os objetivos a serem alcançados através do voleibol em relação à educação devem especificamente abranger as habilidades motoras, a formação de equipes de nível escolar, bem como esquemas táticos, regras gerais e conhecimento de arbitragem. Mas que além disso o profissional busque ofertar a todos, oportunidades de estarem incluídos nas práticas. Esse pensamento apoia-se no que afirma Ferrandis Flores (1988) apud Jordan e Madrona, (1999, p. 23) "entendese a educação obrigatória como um tronco comum de conhecimentos e aprendizagem que deve ter adquirido e desenvolvido a totalidade dos habitantes do país ".

De acordo com esta compreensão, os conteúdos não podem ser propedêuticos, ou seja, seletivos, mas devem resultar na elevação da cultura mínima do país. " Para Santana,

O fato é que em geral há a crença de que o esporte é apenas para quem tem talento, ainda que estes sejam minoria. Por conta disso, quantas crianças têm sido submetidas a um tipo de pedagogia que não respeita as diferenças, que elege os resultados em curto prazo como objetivo e apenas a competição como referencial de avaliação do aprendizado? (...) penso que uma pedagogia comprometida apenas em revelar talentos e formar campeões tende a não se comprometer com os fenômenos humanos. (SANTANA, 2002, p. 176-180).

\section{PROPOSTAS METODOLÓGICAS}

Barroso (2006), apresenta a partir da observação de abordagens pedagógicas que norteiem o ensino da modalidade esportiva dentro do ambiente formal de ensino algumas possibilidades educacionais para a prática esportiva do voleibol na escola. 
Em análise da modalidade no contexto escolar, Paes (2002) apud Barroso (2006), enfatiza quatro situações que prejudicam a didática deste conteúdo em aulas de Educação Física: a) a esportivização das diversas modalidades esportivas sem um objetivo em âmbito escolar; b) a repetição dos mesmos gestos técnicos em diferentes séries de ensino; c) a desorganização dos conteúdos, fragmentando de forma descontinuada os conteúdos; e, e) a especialização precoce que reduz as experiências motoras dos praticantes focando em uma determinada modalidade para obter resultados rápidos.

Em contrapartida, Paes sugere algumas alternativas com embasamento pedagógico para o ensino de esportes na escola: a) entender que o esporte faz parte da cultura popular e atua como ferramenta educacional; b) organizar os conteúdos de forma gradativa; c) respeitar o nível em relação às atividades ofertadas; e, d) disponibilizar variados estímulos motores pela vivência de diferentes modalidades esportivas possibilitando o interesse pela prática cotidiana.

Uma proposta de ensino de voleibol defendida por Mesquita (1998) apud Barroso (2006), é a de que o ensino de voleibol é de "jogo reduzido", possibilitando um maior número de ações de contato do aluno com a bola, em que os esforços dessas ações sejam suficientes para interação com os outros jogadores e executar as sequências de jogadas com sucesso.

Paes (2001) apud Barroso (2006), apresenta uma proposta de estruturação didática dos esportes coletivos no Ensino Fundamental, sendo eles: o basquete, handebol, futebol e voleibol. Visando respeitar a faixa etária em cada série de ensino e definindo os conteúdos de acordo com as características esportivas trabalhadas anteriormente. Para o autor, nas $1^{\underline{a}}$ e $2^{\underline{a}}$ séries, a pré-iniciação deverá trabalhar o conteúdo de manipulação de bola e o domínio do corpo. Já nas $3^{\mathrm{a}}$ e $4^{\mathrm{a}}$ séries, a iniciação I, o conteúdo deverá ser o treino de passe, drible e a recepção. Nas séries finais do Ensino Fundamental, 5ª e 6⿳亠丷a séries, a iniciação II, finalizações e fundamentos específicos; na $7^{\mathrm{a}}$ e $8^{\mathrm{a}}$ séries a iniciação $\mathrm{III}$, onde as situações de jogo transições e sistemas defensivos e ofensivos. 
Como é possível observar, o autor reforça que a utilização das fases garante o desenvolvimento concomitante das etapas posteriores do esporte e que o fato da proposta ser direcionada para as quatro modalidades esportivas não pressupõe que o planejamento escolar ofereça um maior repertório de modalidades.

Magill (2000) aponta que as metodologias analítica e sintética, são as mais utilizadas no ensino das práticas desportivas. A metodologia analítica trabalha as habilidades motoras de forma fragmentada passo a passo, para posteriormente realizar a ação completa, com característica tecnicista; já a metodologia sintética, simplifica as ações de jogo, como medidas da quadra, número de jogadores, altura da rede e adaptação de materiais, voltando-se para o lúdico.

\subsection{AS BASES LEGAIS DAS DISCIPLINAS DESPORTIVAS}

Do foco educacional, a modalidade de voleibol, hoje é obrigatoriamente ofertada nas escolas públicas e privadas, direcionadas por vários documentos legais, que não fazem referências específicas sobre o voleibol, mas, que tem em seus critérios de exigências a respeito dos esportes as seguintes atribuições:

Nos Parâmetros Curriculares Nacionais para Educação Física (BRASIL, 2000), menciona que:

[...] o Ensino Fundamental deverá abranger, três blocos de conteúdo, sendo um deles "esportes, jogos, lutas e ginásticas", tendo-se o conceito de esporte como as práticas em que são adotadas regras de caráter oficial e competitivo, organizadas em federações regionais, nacionais e internacionais que regulamentam a atuação amadora e a profissional (BRASIL, 2000, p. 48).

Nota-se que no contexto destas orientações que as atividades de jogos prédesportivos e os esportes coletivos e individuais do primeiro ciclo (do $1^{\circ}$ ao $5^{\circ}$ ano), sejam posteriormente polidas e ampliadas no segundo ciclo (do 6ํㅜ ao $9^{\circ}$ ano) (PCNs, 2000).

Para a Lei de Diretrizes e Bases da Educação Nacional (LDBEN) 9.394/96 - inciso 2, do parágrafo único, do Art. 1ํ, o "esporte" aparece como conteúdo obrigatório no 
Ensino Fundamental e Médio, pois, "As práticas desportivas formais e não formais, direito de cada um e dever do Estado, serão ofertados no Ensino Fundamental, no Ensino Médio e em todos os cursos superiores." (BRASIL, apud CASTELLANI FILHO, 1998, p. 11-12).

Paes (2002), reforça a importância do esporte no ambiente escolar, que além de ser um conteúdo disciplinar de Educação Física, o fato da escola ser determinante na disseminação e promoção cultural e de justiça social, no sentido de que a oferta de acesso ao esporte alcance um maior número de praticantes, visto que a oferta privada é excludente e seletiva.

\subsection{HISTÓRICOS RECENTES}

Analisando a retrospectiva da carreira desportiva de alguns atletas, percebemos 0 papel fundamental da escola em estimular e pré-condicionar o aluno para a prática do voleibol.

Gilberto Godoy Filho (Giba), um dos melhores jogadores do mundo conheceu o vôlei na escola. Recebeu bolsa de estudos para representar a escola desportivamente, o que favoreceu a conciliação entre o estudo e treinamento.

É importante ressaltar que, em várias localidades do Brasil, clubes e escolas, como também faculdades, têm cedido bolsas de estudo para atletas de diversas modalidades, inclusive o voleibol. Como parcerias, em benefício ao esporte e ao atleta, e porque não da escola.

Bernardo Rocha de Rezende (Rio de Janeiro, 28 de maio de 1959) é um dos mais renomados técnicos de seleções brasileira de voleibol, modalidades feminino e masculino. Além de inúmeras conquistas como treinador é autor dos livros: "Bernardinho - Cartas a um jovem atleta", "Determinação e Talento: O caminho da Vitória" e "Transformando Suor em Ouro". Suas conquistas nas quadras fizeram do treinador um requisitado conferencista, ressaltando em suas palestras valores como trabalho em equipe motivação, resiliência, liderança e abordagens comuns tanto aos 
esportes quanto aos recursos humanos denominada por Bernardo como a "Roda da Excelência". Esses livros hoje fazem parte de um acervo de abordagens educacionais e motivacionais, que transmitem experiências desportivas, capazes de influenciar drasticamente, nas relações entre professor- aluno-conteúdo.

No âmbito local, uma breve retrospectiva dos feitos da modalidade de voleibol em Foz do Iguaçu, demonstra as inúmeras conquistas no cenário estadual, como diversas atuações no cenário nacional. Uma dessas participações nos anos de 2007 e 2008, na Super Liga Nacional, considerado o segundo maior campeonato de voleibol do mundo, onde estão alguns dos melhores jogadores do planeta. Essa participação foi fruto de um trabalho a longo prazo de formação, capacitação e divulgação da modalidade na cidade.

A equipe não teve resultados muito expressivos, porém, como conquista maior, angariou muitos adeptos à prática do esporte na cidade. Esses em sua maioria jovens em fase escolar. Pode-se observar que desde a participação na liga nacional de voleibol houve um aumento significativo de projetos de instituições particulares de ensino de incentivo a esta modalidade esportiva, tais iniciativas investem em tanto na estrutura física e educativa na formação dos atletas e equipes que representem a instituição e a cidade em competições regionais, estaduais e nacionais.

\subsection{ENTREVISTAS}

Foram entrevistados alunos do Ensino Fundamental, séries finais, de cinco (5) instituições de ensino de Foz do Iguaçu. Sendo duas da rede pública de ensino e três da rede privada de ensino. Ao todo, foram selecionados dez (10) estudantes de cada instituição, totalizando cinquenta entrevistados.

As questões aplicadas aos entrevistados possuíam conteúdo específico e eram de cunho subjetivo, para que fosse possível interpretar melhor as condições individuais de cada aluno para a prática esportiva, como também buscar a compreensão sobre a percepção que o estudante possui sobre a estrutura da escola para a prática do voleibol. 
Por esta razão, a pesquisa de campo realizada neste estudo buscou aprofundar as questões propostas distribuídas pela população, isto é, neste modelo clássico de investigação, a pesquisa é desenvolvida por meio da observação direta das atividades do grupo estudado e de entrevistas com informações, explicações e interpretações do que ocorre com o grupo (GIL, 2007).

Gráfico 1: Questão ํo 1

\section{Qual o nome das funções dos jogadores? Marque as alternativas corretas.}

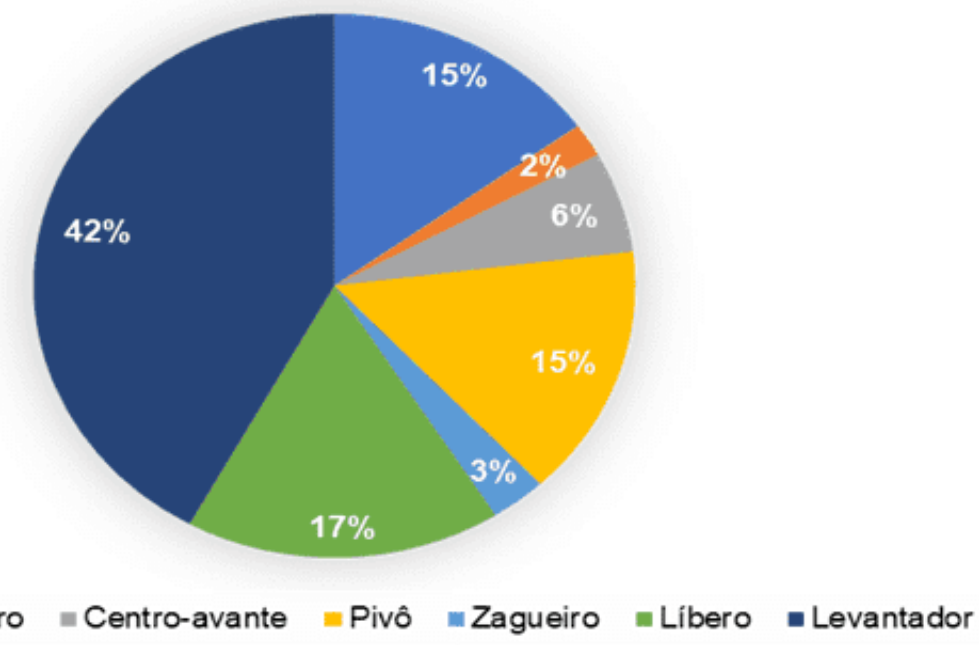

Fonte: elaborado pelos autores.

Os alunos não têm muita afinidade com o nome das funções dos jogadores, sendo que nenhum acertou todas as alternativas sem acrescentar funções de outras modalidades esportivas. Vale destacar, porém, que não há muita relevância quanto ao exercício da modalidade, todavia, é necessário que estas funções sejam definidas quando a modalidade é disputada com regras oficiais. Nesse sentido, o fato de o estudante nunca ter efetuado qualquer uma dessas funções compromete seu aprendizado, coloca-se em dúvida o domínio do conteúdo teórico-prático e de didática, por parte do professor, e de suas atualizações em relação as funções dos jogadores. 
Gráfico 2: Questão № 2

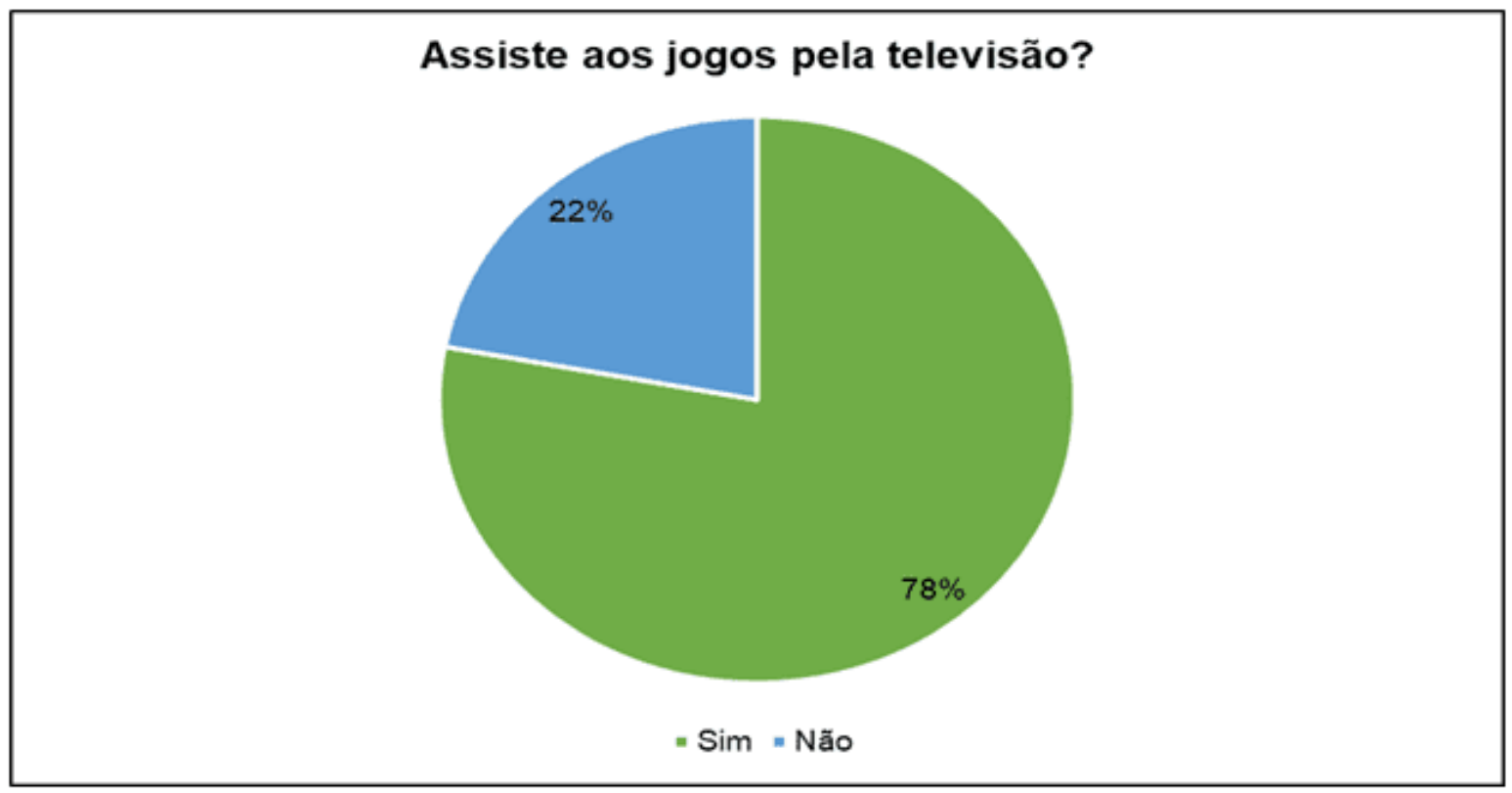

Fonte: elaborado pelos autores.

A maioria dos entrevistados afirmou que acompanha aos jogos pela televisão, o que acaba por reforçar o aprendido na escola. Um aspecto interessante a se pontuar está diretamente relacionado com a opinião crítica trazida pelos alunos que acompanham o voleibol por meio das transmissões televisionadas, isto é, além de ser uma fonte para o surgimento de dúvidas que devem ser esclarecidas em sala de aula, o esporte ao ser transmitido pela televisão aberta, possibilita aos estudantes motivarem-se para sua prática nas aulas de educação física escola. Todavia, é preciso pontuar que, além do aspecto positivo mencionado, há também o fator negativo de se apresentar um jogo muito regrado e com caráter espetacular, mostrando jogadores de porte longilíneo, o que indiretamente desestimula os de caráter oposto. 
Gráfico 3: Questão ํㅡ 3

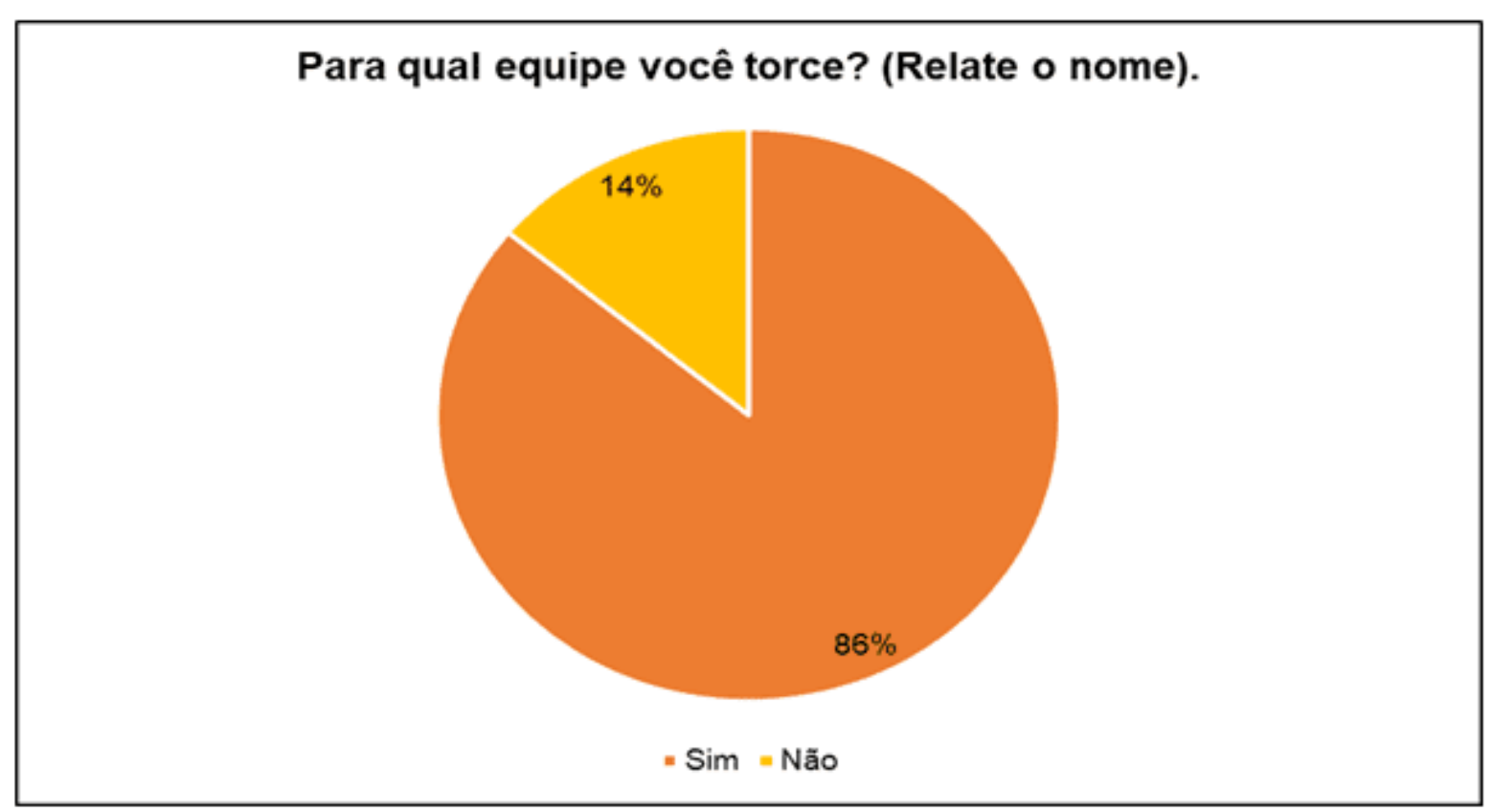

Fonte: elaborado pelos autores.

A maioria dos entrevistados revelou torcer por uma equipe de voleibol, sendo que o nome mais citado, foi o da seleção brasileira. Isso se deve talvez pela falta de proximidade de uma equipe profissional, ou talvez pela pouca realização de jogos televisionados. O fato de a seleção brasileira de vôlei ser admirada pelos jovens, reforça a questão do exemplo transmitido pelos atletas. As histórias de vida, a superação, o esforço, a alegria das conquistas, são os pontos positivos a serem explorados. 
Gráfico 4: Questão № 4

\section{A sua escola possui equipe de voleibol de base?}

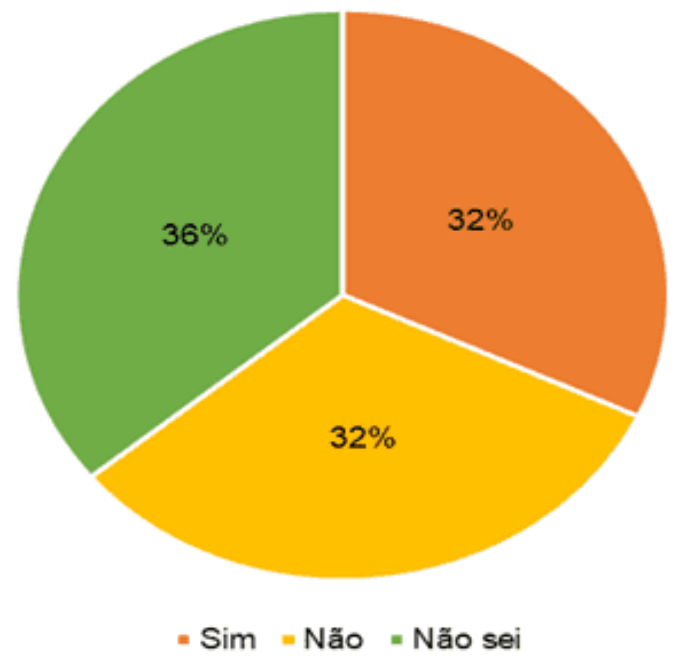

Fonte: elaborado pelos autores.

Apenas uma instituição de ensino em que se realizou o estudo possui equipe de base, as demais estão iniciando seus trabalhos de formação de equipes para os jogos escolares, o que justifica a alternância das respostas. O fato de apenas uma instituição de ensino possuir equipe de voleibol, sendo esta particular, demonstra que ainda há muitos desafios para as instituições públicas lançar seus talentos esportivos em competições locais, regionais, estaduais e em nível nacional. Além disso, percebemos que, para a instituição que possui sua equipe escolar de voleibol a questão não se trata apenas de investimento financeiro no esporte (contratação de profissionais, bolsas de estudos e estruturação) com retorno deste, mas de um processo de formação cidadã que vai de encontro à função social da escola enquanto instituição formativa. 
Gráfico 5: Questão 5

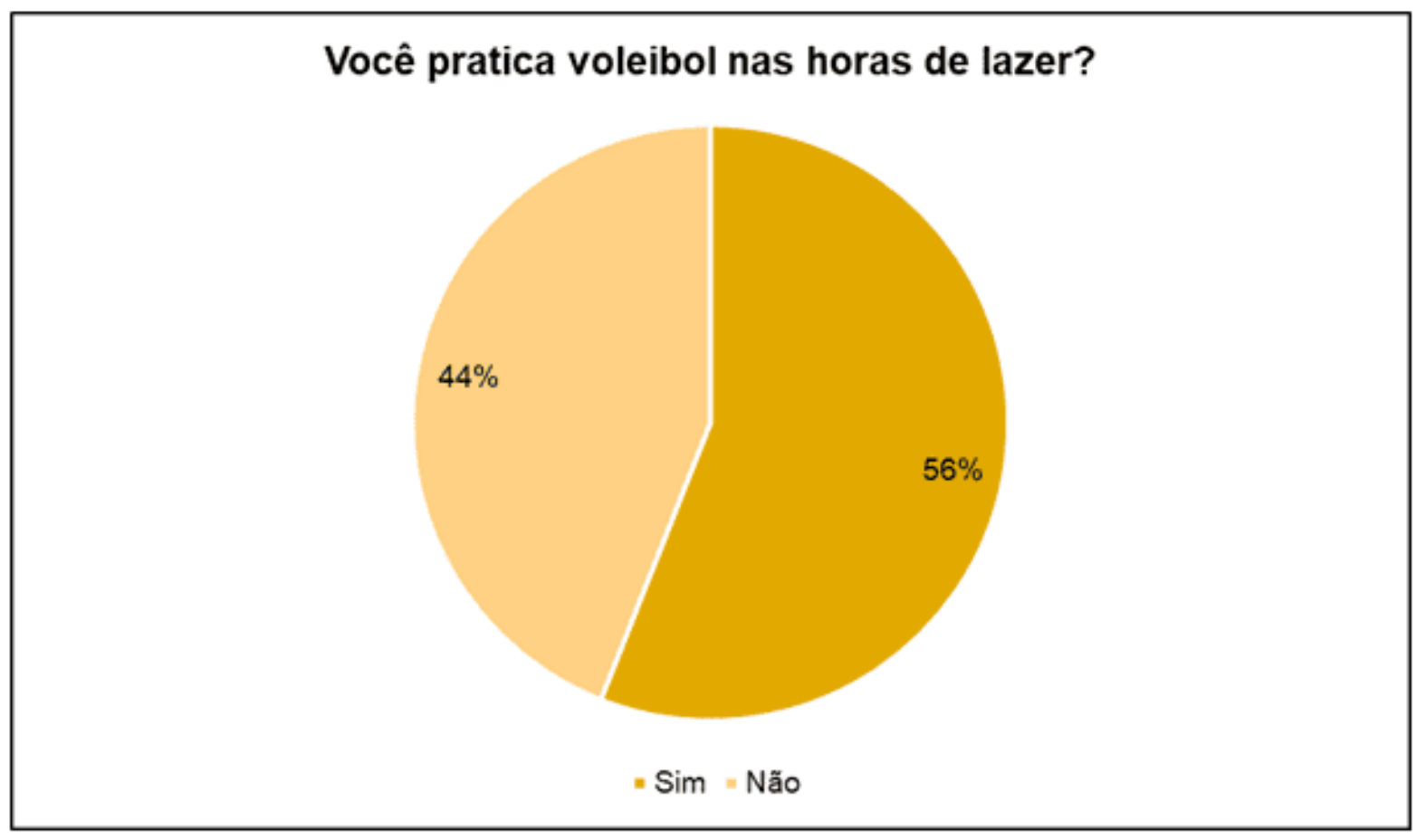

Fonte: elaborado pelos autores (2009).

A prática de esportes nos horários de lazer define a preferência do indivíduo por determinada modalidade, como também as oportunidades oferecidas para sua prática fora do ambiente escolar. Jogos de rua, em quadras comunitárias e até em áreas livres ou dentro de casa proporcionam essas oportunidades. A presença de materiais como bola e rede nesses ambientes, quantificam e qualificam essas oportunidades, tornando-as próximas da realidade exigida em jogos oficiais.

Caso o aluno não praticasse voleibol nos horários de lazer, quais os principais motivos que interferiam na sua prática. A maioria afirmou que não há espaços disponíveis para praticar o esporte, outros disseram ainda que não gostam e, ainda, há os que dizem não ter altura suficiente, conforme mostra o gráfico número 6. 
Gráfico 6: Questão ํㅜ 6

\section{Se não pratica voleibol, quais são as principais razões?}

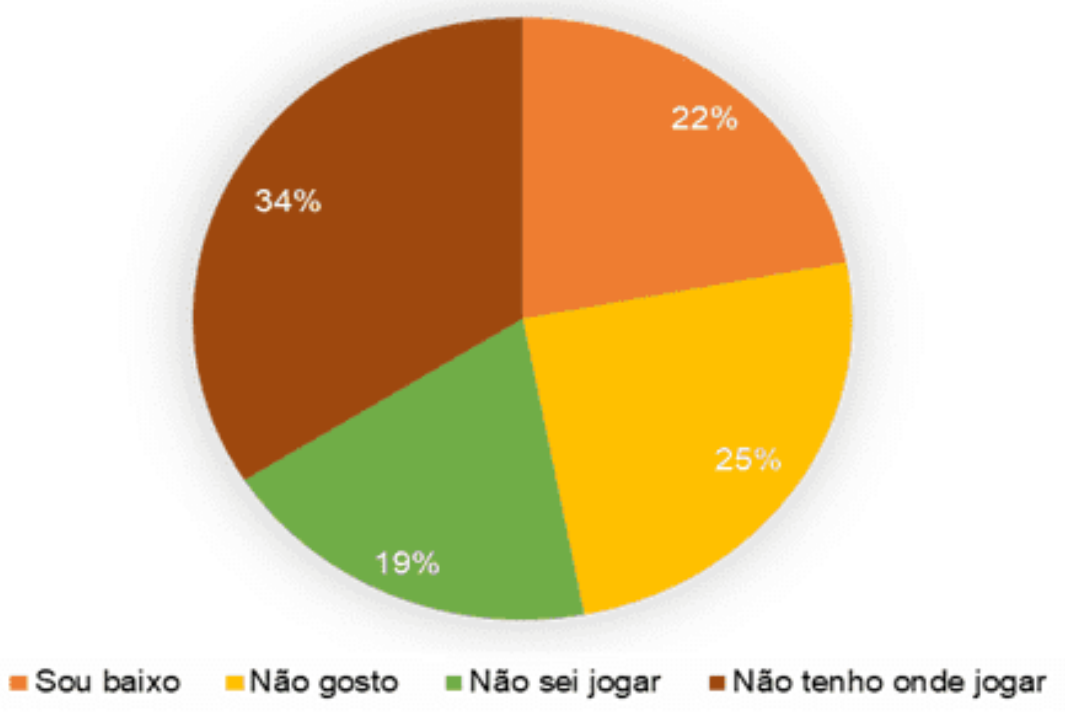

Fonte: elaborado pelos autores (2009).

Conforme os dados apresentados no gráfico, e tendo em vista o processo urbanístico e de organização dos bairros em que estão situadas as instituições de ensino pesquisadas, as respostas dos entrevistados revelam uma coerência da indisponibilidade de locais na região para a prática do esporte nos horários de lazer dos estudantes e demais moradores. Além disso, observa-se também que, dos espaços disponíveis para a prática do voleibol, outras modalidades esportivas de maior assédio acabam por serem mais privilegiadas nestes locais. Ademais, não saber jogar, ser baixo ou não gostar, pode ser o fato da supervalorização competitiva imposta por outros praticantes ou educadores. Portanto, a presente questão demonstra que necessário desenvolver a presença do lúdico em todos os ambientes em que se prática de voleibol, incluindo praticantes desprezados e atraindo os que dizem não gostar. 
Gráfico 7: Questão 7

\section{Seus pais ou irmãos praticam voleibol?}

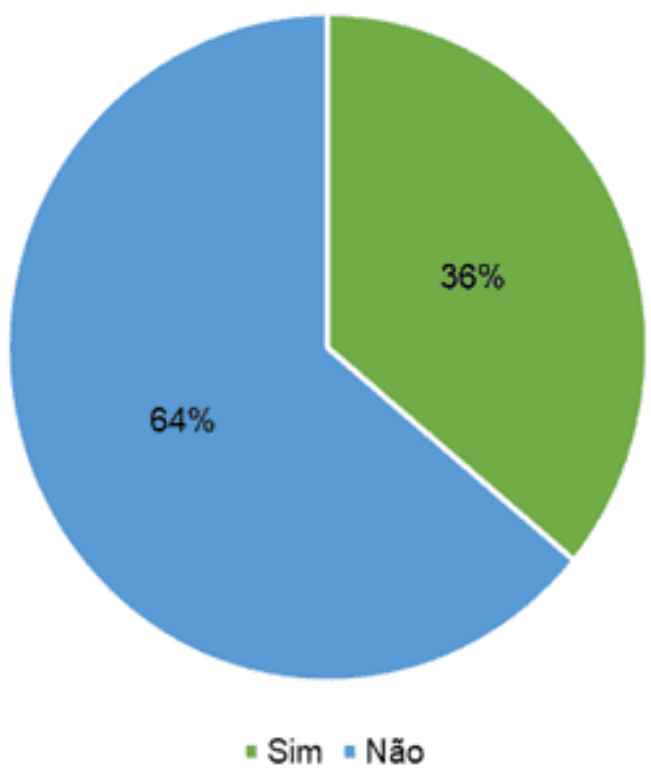

Fonte: elaborado pelos autores (2009).

A prática da modalidade por parte dos pais ou irmãos revela a influência familiar, quanto ao incentivo e a repressão. $O$ incentivo quando muitas vezes os pais são exatletas ou simpatizantes e, quando seus irmãos são uma referência, sendo praticantes e testemunhando os benefícios e prazeres advindos do esporte. No aspecto de repressão, pode-se inferir que quando os pais são sedentários, não simpatizantes ou que nunca tiveram nenhum contato com o esporte, pode ser fator para que o jovem perceba a prática esportiva como algo de menor importância para a saúde física e mental dos indivíduos e isto faz com que o esporte seja marginalizado ou menosprezado por aqueles que responderam que não o praticam. Além disso, trabalhos domésticos, trabalhos no auxílio da renda familiar e outras ocupações impostas, são agentes que comprometem o tempo disponível fora do ambiente escolar. 
Gráfico 8: Questão 8

\section{Quais são os fundamentos do voleibol?}

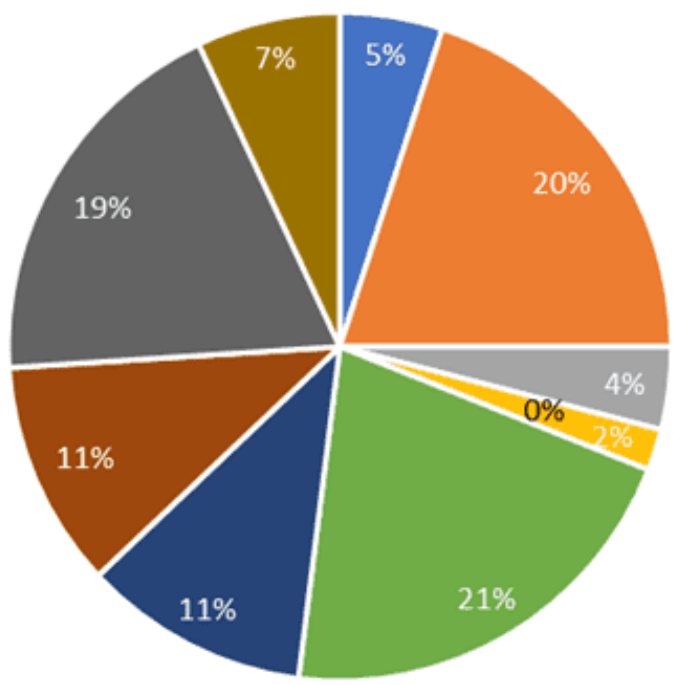

- Arremesso $=$ Manchete $=$ Passe $=$ Bandeja " Drible $=$ Saque - Toque - Defesa $=$ Bloqueio - Ataque

Fonte: elaborado pelos autores (2009).

Quanto aos fundamentos do voleibol, os nomes ainda são confundidos com os do basquete, mesmo assim, os estudantes demonstraram conhecimento dos principais fundamentos necessários para a realização de uma partida. Nesse aspecto, pontuamos que a confusão com os fundamentos de outros esportes está diretamente relacionada com a didática adotada pelo professor de Educação Física e a importância que este dá ao conteúdo esportivo ministrado nas aulas teóricas da disciplina. 
Gráfico 9: Questão 9

\section{Sua escola possui materiais para a prática de voleibol (rede, quadra, bola)?}

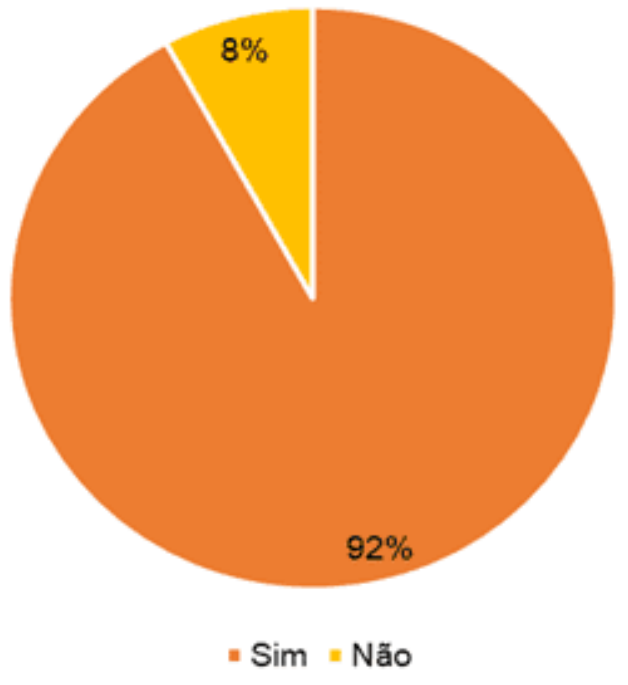

Fonte: elaborado pelos autores (2009).

Quanto aos fundamentos do voleibol, os nomes ainda são confundidos com os do basquete, mesmo assim, os estudantes demonstraram conhecimento dos fundamentos necessários para a realização de uma partida. Entretanto, vale salientar que, a resposta dada pelos entrevistados demonstra que a didática adotada por professores de Educação Física é pouco precisa em relação aos fundamentos teóricos do voleibol.

Apenas as escolas públicas tiveram respostas negativas, as demais, que são instituições particulares de ensino, $100 \%$ dos entrevistados afirmaram haver os materiais necessários. Subentende-se que as escolas públicas, por este fato, dificultam o desempenho do educador e do educando. Se somados a ausência desses materiais a falta de habilidade didática do professor, resultam em perda para o aluno. 


\section{CONSIDERAÇÕES FINAIS}

Levando-se em consideração os dados coletados e analisados, conclui-se que fica evidente os fatores que influenciam no estímulo e no desestimulo à prática do voleibol nas escolas de Ensino Fundamental e Médio de Foz do Iguaçu são:

Primeiramente, as características educacionais das instituições de ensino apontam para a questão da didática, isto é, pouco eficaz e que valoriza a competição, deixando de lado o lúdico. A falta de domínio, por parte do professor, do conteúdo aplicado, juntamente com a escassez de materiais e estrutura física das escolas, comprometem resultados qualitativos e quantitativos.

Outro aspecto relevante é o trabalho antecipado das valências físicas nas fases educacionais do ensino infantil e anos iniciais da escolarização básica. O não trabalho destas valências, a longo prazo deixa lacunas no desenvolvimento psicomotor do aluno.

É preciso salientar que, fatores de ordem sócio-políticas indicam a falta de locais para prática do vôlei, bem como o desinteresse das autoridades em promoverem oportunidades de massificação do esporte em questão. A influência dos pais e parentes é de grande notoriedade, principalmente fora do ambiente escolar, tanto motivando, apoiando, como até mesmo ocupando o tempo livre dos jovens impondo várias tarefas.

A mídia tem grande poder de sugestão, o que indica que sua influência em questão é de fundamental importância no estímulo e no ganho de conhecimento a respeito do voleibol e suas características de sociabilização, cooperativismo e bem estar físico.

Portanto, a responsabilidade do profissional de Educação Física está em encontrar estratégias que supram as demandas, de forma a transpor os obstáculos já conhecidos, e oferecer variados ângulos na forma do aluno enxergar o voleibol em seu contexto pessoal, demonstrando que todos, apesar de suas limitações, sejam elas físicas ou intelectuais, são bem-vindos e são importantes para o grupo. 


\section{REFERÊNCIAS}

ARAUJO, J. B. Voleibol Moderno: Sistema defensivo. Rio de Janeiro: Grupo Palestra Sporte,1994.

BARROSO, A. L. R.; DARIDO, S. C. O Voleibol na Escola: Estudo de Propostas Metodológicas. Disponível em: <http://cev.org.br/eventos/x-enfefe-encontrofluminense-educação-física-escolar>. Acesso em: 24 set. 2009.

BRASIL. Ministério da Educação. Parâmetros Curriculares Nacionais (PCN): Educação Física. Secretaria de Educação Fundamental. 2. ed. - Rio de Janeiro: DP\&A, 2000.

CASTELLANI FILHO, L. Política educacional e educação física. Campinas, SP: Autores Associados, 1998.

CONFEDERAÇÃO BRASILEIRA DE VOLEIBOL. Revista Voleibol Técnico. Rio de Janeiro, 1995.

GIL, A. C. Como elaborar Projetos de pesquisa. 4 ed. São Paulo: Atlas, 2007.

JORDAN, O. R. C.; MADRONA, P. G. Formação inicial do professor de educação física: estudo de caso escola de Magistério de Albacete. Espanha. Revista Paulista de Educação Física, n. 13, v-1, p. 22-33, jan./jul. 1999.

MAGILL, Richard A. Aprendizagem Motora: conceitos e aplicações. São Paulo: Edgard Blücher, 2000.

MESQUITA, I.; GUERRA, I.; ARAUJO, V. Processo de formação do jovem jogador de voleibol. Lisboa: Heska Portuguesa, S.A. 2002.

MESQUITA, I. O ensino do voleibol: proposta metodológica. In: GRAÇA, A; OLIVEIRA, J. (Ed.). O ensino dos jogos desportivos. 3. ed. Universidade do Porto, 1998. 
PAES, R. R. A pedagogia do esporte e os jogos coletivos. In: ROSE JR., D. de (Org.). Esporte e atividade física na infância e na adolescência. Porto Alegre: Artmed, 2002.

SANTANA, W. C. Iniciação esportiva e algumas evidências de complexidade. In: Simpósio de Educação Física e Desportos do Sul do Brasil, XIV, 2002, Ponta Grossa. Anais Ponta Grossa: Universidade Estadual de Ponta Grossa, 2002.

SCARPATO, M. Educação Física: Como planejar as aulas na Educação Básica. São Paulo: Avercamp. 2007.

Enviado: Dezembro, 2020.

Aprovado: Janeiro, 2021. 